\title{
JAXA's S4 Supersonic Low-Boom Airliner - A Collaborative Study on Aircraft Design, Sonic Boom Simulation, and Market Prospects
}

\author{
Bernd Liebhardt ${ }^{\mathrm{a}}$ and Klaus Lütjens ${ }^{\mathrm{b}}$ \\ German Aerospace Center (DLR), Hamburg, Germany \\ Atsushi Ueno ${ }^{\mathrm{c}}$ and Hiroaki Ishikawa ${ }^{\mathrm{d}}$ \\ Japan Aerospace Exploration Agency (JAXA), Tokyo, Japan
}

\begin{abstract}
In this work, the design methodologies and technical rationales for the design of JAXA's low-boom S4 (System integration of Silent SuperSonic airplane technologies) airliner are detailed with a focus on aerodynamic engine-airframe integration with respect to efficiency and sonic-boom abatement, respectively. The approach to high-fidelity CFD grid generation, flow simulation, and signature propagation for sonic boom assessment is explained, resulting in sonic-boom data maps with respect to flight physics parameters. Thereafter, DLR inserts the aircraft in operational scenarios for supersonic overland prohibition and permission, respectively, based on forecasted origin-destination passenger demand. Overwater flight routes are designed for the restrictive scenario, and the S4's flight performance data are used to simulate flight missions on all routes, yielding flight durations. Eventually, the respective market sizes for S4-type airliners are estimated and discussed.
\end{abstract}

\section{Introduction}

$\mathrm{T}$ The Japanese and German national institutions of public aerospace research, JAXA and DLR, have been cooperating in the field of civil supersonics and particularly, on aspects of sonic boom, for several years. Whereas JAXA specializes in low-sonic boom aircraft design, DLR's peculiarity lies in operational and economic assessments. (Coincidentally, both possess and develop advanced tools for high-fidelity computational fluid dynamics (CFD).) This study approaches an issue that requires both partners' competencies, namely assessing the market prospects of an airliner configuration especially designed and approved for supersonic overland flight. JAXA provides the airliner's technical specifications which DLR then inserts into a global operational scenario.

\section{Design and performance of S4-1.3.4th configuration}

Japan Aerospace Exploration Agency (JAXA) performed research and development program named S4 (System integration of Silent SuperSonic airplane technologies) to obtain key technologies realizing an environmentally friendly and economically viable supersonic transport. In this program, four technical targets are set as follows; a) the sonic boom loudness should be decreased to less than 85 PLdB (Steven's mark vii perceived level) to realize overland supersonic flight, b) the airport noise should be decreased to comply with ICAO noise standards (Chapter 14), c) the cruise lift-to-drag ratio (L/D) should be improved to 8 to realize flying range of $3,500 \mathrm{~nm}$, and d) the structural weight should be decreased by $15 \%$ as compared to the Concorde technology (i.e., without use of composite material). To achieve these targets, research and development on element technologies, such as low-boom design, natural laminar flow (NLF) wing, high-lift device, and low-noise nozzle, is conducted. These results are applied to conceptual design of 50 -seat-class supersonic twin-engine airliner. Its final version is S4-2 ${ }^{\text {nd }}$ configuration. In this joint study, its earlier version, S4-1.3.4 ${ }^{\text {th }}$ configuration shown in Figure 1, is used.

In the design of S4-1.3.4 ${ }^{\text {th }}$ configuration, the propulsion/airframe integration is focused on [1]. The engines have larger bypass ratio than existing supersonic engines in order to comply with ICAO noise standards, which results in

${ }^{a}$ PhD; Researcher; Air Transportation Systems, Blohmstrasse 20, 21079 D-Hamburg, AIAA Member.

${ }^{\mathrm{b}}$ Head of Department; Air Transportation Systems, Blohmstrasse 20, 21079 D-Hamburg, Non-AIAA Member.

c Researcher, Aeronautical Technology Directorate, 6-13-1 Osawa, Mitaka, Tokyo, AIAA Member.

d Senior Researcher, Aeronautical Technology Directorate, 6-13-1 Osawa, Mitaka, Tokyo, AIAA Senior Member. 
larger engine diameter. Thus, the efficient engine layout is needed to reduce both drag and sonic boom loudness. In the S4-1.3.4 $4^{\text {th }}$ configuration, the engines are mounted on the side fuselage. This layout reduces wing pressure drag because the intake shock wave acts on the trailing edge of the wing and pressure recovery is enhanced. Furthermore, the intake shock wave is prevented from propagating to the ground. As a result, the sonic boom loudness is also reduced. Another topic of propulsion/airframe integration is the effect of engine plume on the sonic boom loudness. The engine plume generates compression and expansion waves. The latter has negative impact on the sonic boom loudness because negative pressure in the rear boom is enhanced by the expansion wave. To prevent the expansion wave from propagating to the ground, the shielding fin is placed in the downstream of the nozzle exit.

Performance of the S4-1.3.4 $4^{\text {th }}$ configuration is as follows. The sonic boom loudness at the cruise condition is 87.6 PLdB. The technical target (85 PLdB) is successfully achieved in S4- ${ }^{\text {nd }}$ configuration by reshaping the fuselage to smoothen the equivalent area distribution. The cruise L/D of S4-1.3.4 ${ }^{\text {th }}$ configuration is 7.8 , while a NLF wing is applied to S4-2 ${ }^{\text {nd }}$ configuration, and $\mathrm{L} / \mathrm{D}$ is improved to 8 . As for the airport noise, the Krueger flap is studied to improve L/D at take-off without degrading NLF wing performance. The low noise nozzle along with the Krueger flap is applied to S4-2 ${ }^{\text {nd }}$ configuration to comply with ICAO Chapter 14.

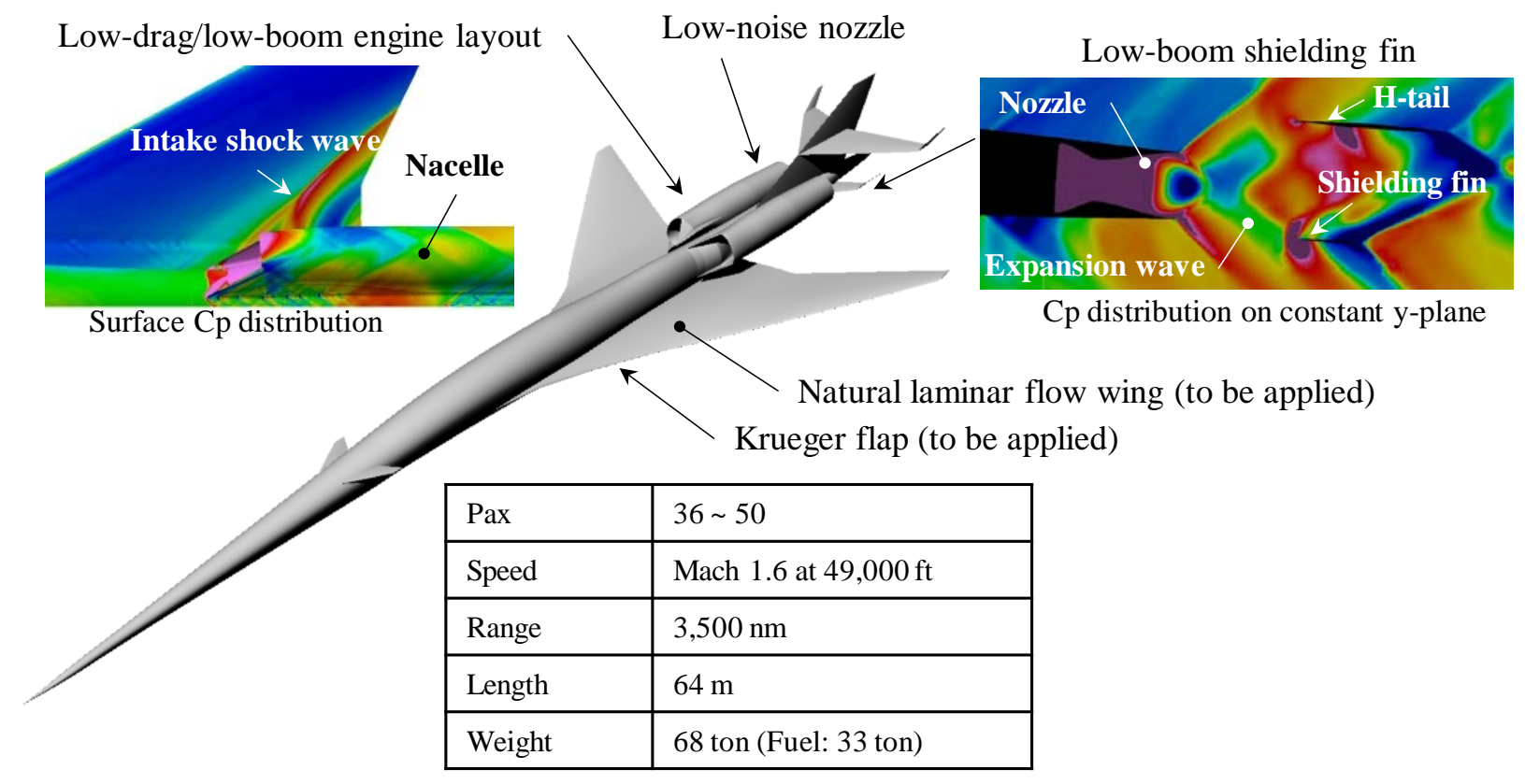

Figure 1. JAXA S4-1.3.4 ${ }^{\text {th }}$ configuration

\section{A. Numerical method}

The CFD analysis is conducted with an Unstructured/Structured grids hybrid method [2]. This hybrid method uses an unstructured grid by TAS (Tohoku university Aerodynamic Simulation) [3] code in the vicinity of the aircraft that is a complex configuration, and a structured grid by UPACS (Unified Platform for Aerospace Computation Simulation) [4] code far from the aircraft. Figure 2 shows the computational grid and Figure 3 shows the representative pressure distribution of the calculation results. The computational grid of this paper corresponds to the fine resolution viscous grid of the $2^{\text {nd }}$ Sonic Boom Prediction Workshop (SBPW2), called "080 scale". The TAS code is based on a cell-vertex finite volume method, in which the HLLEW (Harten-Lax-van Lee-EinfeldWada) method is used for the numerical flux computations, and the second-order spatial accuracy is obtained by a linear reconstruction of the primitive variables. The Venkatakrishnan flux limiter is applied. The Spalart-Allmaras turbulence model is used in the Reynolds-averaged Navier-Stokes (RANS) simulations for the unstructured grids. The LU-SGS (Lower/Upper Symmetric Gauss- Seidel) implicit method is used for the time integration. The UPACS code for the structured grid is based on a cell-centered finite volume method, in which the convection terms of the governing equations are discretized using AUSMDV scheme with MUSCL interpolation and van Albada limiter. MFGS (Matrix Free Gauss-Seidel) implicit method is used for time integration. The turbulence model is not applied to the structured grid simulation because the simulation region of the structured grid is located in the far from the aircraft. The unstructured grid has 20 million nodes and 75 million cells, and the structured grid has 50 million nodes. Figure 4 shows the obtained near field pressure signature on interrogation line far from the three body lengths 
$(H / L=3)$ on the design condition $(M=1.6, \alpha=4.0 \mathrm{deg}$, Altitude $=49,000 \mathrm{ft}$.$) . The sharp near-field pressure$ signature is obtained by the Unstructured/Structured hybrid method.

In order to estimate sonic boom loudness on the ground, the near-field pressure signature calculated with the hybrid CFD analysis is modified by the multi-pole analysis (MPnoise [5]) with 20 poles. And it is propagated with the atmospheric propagation code (Xnoise $[6,7])$ to obtain the ground signatures including a ground reflection factor of 1.9. The sampling rate is $48 \mathrm{kHz}$. By solving the augmented Burgers equation, Xnoise takes into account the effect during propagation within the atmosphere due to nonlinearity, stratification of the atmosphere, molecular relaxations, and thermoviscous absorption. All propagation results in this paper assume an atmosphere condition with no-wind US Standard Atmosphere [8], the atmospheric humidity model from ANSIS1.26, Annex C [9] and no atmospheric turbulence as same as SBPW2. And then, using the simulated sonic boom signature on the ground, the perceived level loudness (PLdB) on the ground is estimated to evaluate the low boom performance and create sonic boom data map of the S4 airplane. The sonic boom loudness of the S4 airplane under design cruise condition is estimated to be 87.6 PLdB.

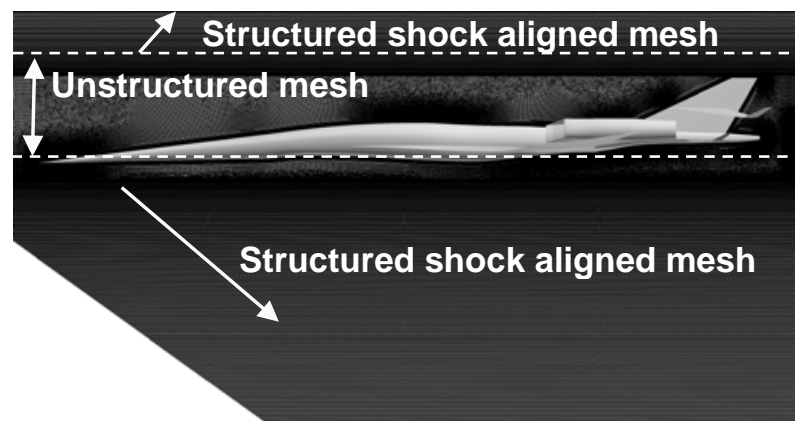

Figure 2. Unstructured/Structured hybrid mesh

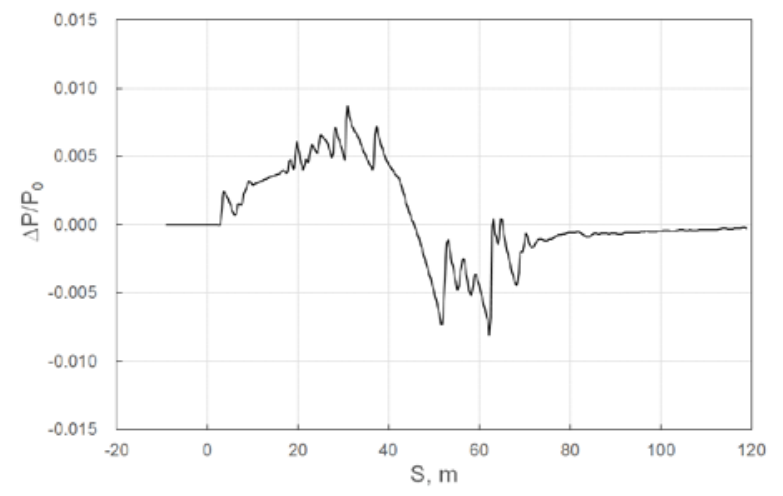

Figure 4. Near-field pressure $(H / L=3)$

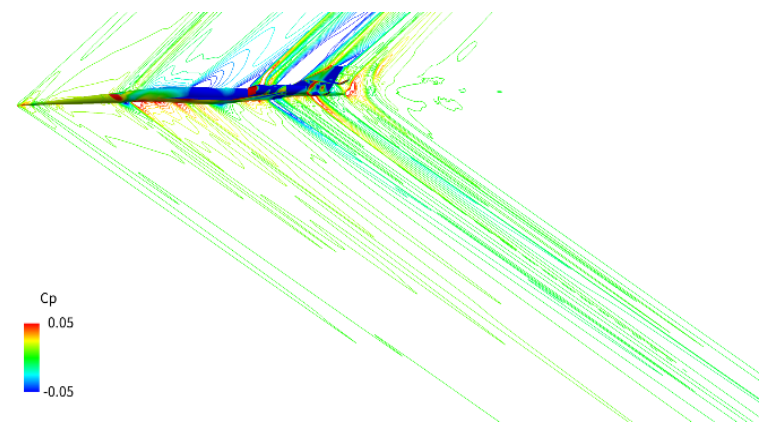

Figure 3. Pressure distribution of CFD result

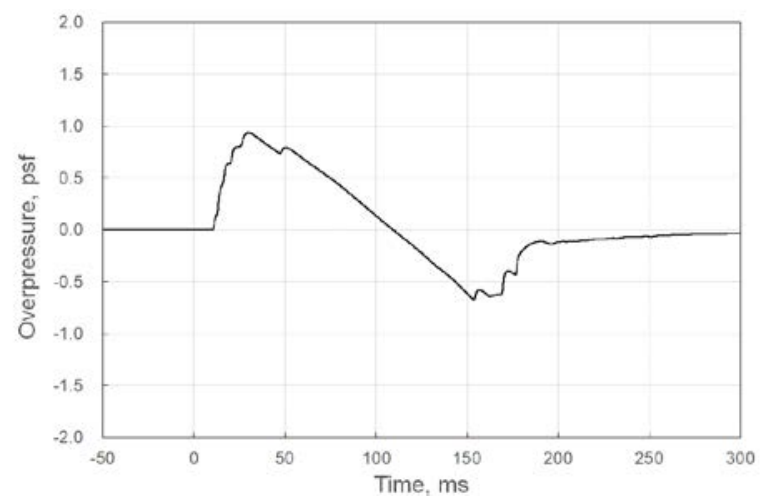

Figure 5. Sonic boom on the ground

\section{B. Sonic boom data map}

The flight conditions are variable during climb, cruise, and descent phases. The sonic boom loudness depends on the variety of flight condition. The contributing factors for the sonic boom estimation should be considered as follows:

1) Mach number

2) Angle of attack related to lift and aircraft weight

3) Altitude

4) Acceleration/deceleration

5) Flight path angle.

The Mach number, the angle of attack and the viscosity (\#1-\#2) are parameters for the CFD analysis to obtain the near-field pressure signature. The other parameters (\#3-\#5) are applied for the propagation simulation to obtain the ground signature of the sonic boom. The viscosity effect is taken into account by giving the Reynolds number to the calculation condition of the CFD analysis. The calculation load of the CFD analysis related on the \#1, \#2 and the Reynolds number is larger than that of the propagation calculation. In order to reduce the overall simulation load, it 
is effective to reduce the parameters of the CFD analysis. It has been reported that the effect of the Reynolds number is negligible compared to the other contributing factors as long as a representative flight Reynolds number is given [10]. The Reynolds number of the design condition is given to all CFD analysis in this study. Further, the lateral conditions such as side slip angle and flight path azimuthal angle are also included as the other contributing factors. However, longitudinal movement is dominant during the entire supersonic flight of general commercial transporter. In this study, the sonic boom assessment is considered only on bilateral symmetry condition. Compared to the entire flight time, the time consumed by the flight path angle change is instantaneous and intermittent. The rate of change of flight path angle is excluded from the contributing factors list as described above.

In order to conduct flight mission analysis, an aerodynamic data map that fully covers the flight condition range during climb, cruise, and descent phases is required. The data map for aerodynamic data and sonic boom loudness under various flight conditions were obtained from the above numerical analysis. Table 1 shows the range of the flight conditions regarding the contributing factor to define the data map. The flight Mach number is considered starting from $M=1.2$, because the sonic boom around the speed of sound may become cut-off. The cut-off phenomena are needed another numerical analysis method. Thus, the flight velocity is varied from $M=1.2$ to $M=$ 1.6 (cruise Mach number) every 0.1. The 35 cases of the CFD analysis and the 90 cases of the propagation simulations par 1 CFD analysis (total 3,150 cases) have been conducted. Figure 6 shows the response surface of the sonic boom loudness around the design point. Under acceleration conditions below $M=1.3$ as shown in Figure 6(c), the ray tube area is detected negative in the propagation analysis. In case of negative ray tube area, it is speculated that sonic boom focusing has occurred. The analysis of the focus boom requires the application of a different analysis method. In this study, a high value of 200 PLdB is given to the data map so that it could not be selected for the flight mission analysis. The altitude is sensitive for the sonic boom loudness as show in Figure 6(b). The loudness is over $100 \mathrm{PLdB}$ under the $40,000 \mathrm{ft}$. altitude. Since supersonic aircraft in a climb and ascending should flight at low altitudes, this result indicates that not only cruise flight phase, but also low boom performance during climb flight must be considered.

Focusing on the sensitivity of sonic boom loudness by flight conditions, the overall sonic boom loudness is low at the cruising Mach number $(M=1.6)$. This is the effect the $\mathrm{S} 4$ airplane was designed to reduce the sonic boom at Mach number 1.6 of the cruise flight condition. In other regions, there seems to be low sonic boom loudness at Mach number 1.3. As shown in Figure 6(a), there is a localized change in the angle of attack. The sonic boom loudness becomes larger at the off-design angle of attack. As shown in Figure 6(b), there is a large change in response to change. It is obvious that at lower altitudes, large sonic booms will be observed on the ground before the noise is sufficiently attenuated. Also, as mentioned above, it is worth noting the increase in sonic boom loudness and the occurrence of focus booms during accelerated flight, as shown in Figure 6(c). On the other hand, Figure 6(d) shows that the sensitivity of sonic boom loudness is low in the range of flight path angle changes for airliner.

The following chapters describe a market assessment that incorporates a wide range of aerodynamic (lift and drag) data maps in addition to the sonic boom loudness described above.

\begin{tabular}{|c|c|c|c|c|c|}
\hline & min. & $\max$. & $\Delta$ & cases & simulations \\
\hline Mach & 1.2 & 1.6 & 0.1 & 5 & CFD \\
\hline Angle of attack, deg. & 2 & 6 & $1(+3.5,4.5)$ & 7 & (35 cases) \\
\hline Altitude, $\mathrm{ft}$ & 20,000 & 60,000 & 10,000 & 5 & \\
\hline Acceleration, $\mathrm{m} / \mathrm{s}^{2}$ & -1.5 & 1 & 0.5 & 6 & - Propagation \\
\hline Flight-path angle, deg & -3 & 3 & 3 & 3 & \\
\hline
\end{tabular}

Table 1. Range of the data map

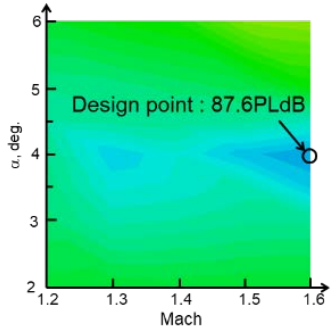

a) Mach-Angle of attack

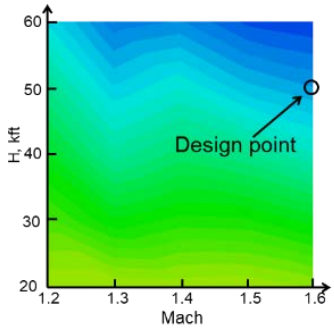

b) Mach-Altitude

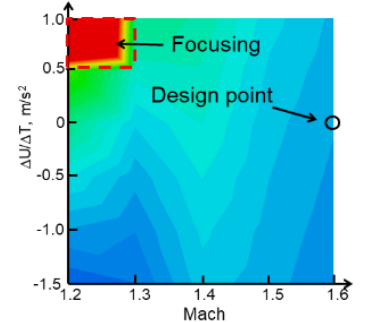

c) Mach-Acceleration

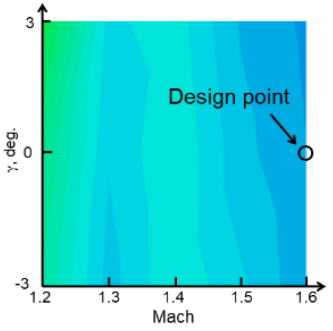

d) Mach-Flight path angle

Figure 6. Response surface of the sonic boom loudness

4

American Institute of Aeronautics and Astronautics 


\section{Supersonic airline market basics}

The following assessment's purpose is the comparison of the market for the S4 supersonic airliner in case of supersonic overland flight prohibition and permission, respectively.

Hereafter, the economic and political environments that a supersonic airliner has to comply with are summarized by considering the main stakeholders: passengers, airlines, the manufacturer, and the public (i.e. politics).

Passenger perspective. Travelers will mainly choose supersonic flight for two reasons: its time advantage, and its perception of prestige. Whereas the latter plays an important role, its influence is hard to quantify. Time advantage, however, can be calculated by simply subtracting supersonic flight times from subsonic ones (whereas in reality, the respective flight schedules carry more importance for the flights' benefit to the passenger). Flight time saving is arguably relevant both in an absolute and in a relative manner: A fixed absolute time saved (e.g. one hour) loses weight the longer the flight takes (e.g. ten hours). A fixed relative time saved (e.g. 50\%) becomes less important for shorter flights (e.g. one hour).

Moreover, tickets for supersonic flight will most probably be very expensive due to the high cost of development and operation (especially fuel burn). Thus, passengers will recruit mainly from the airlines' Business and First Class cabins. Coincidentally, the premium passenger segment is believed to exhibit a low price elasticity, which means that with varying ticket price, demand will change underproportionately: New passengers will hardly be found by lowering fees, and existing passengers will hardly be lost by increasing fees. This means that the passenger pool to draw from is relatively static from a ticket price perspective.

Further, those premium passengers will embrace a choice of flight frequencies, particularly for supersonic flight which is supposed to save them time and to fit their work schedules. Therefore, supersonic airline operations need to incorporate reasonable flight frequencies (e.g. at least once daily).

Airline perspective. Heritage network carriers will have trouble simply adding supersonic airliners to their fleets, because at first instance, many of their passengers would simply move from the subsonic premium cabins to the supersonic aircraft. This would not generate much additional revenue (if any at all), but significant additional capital and operating cost, respectively, rendering the business case moot. For traditional airlines, introducing supersonic aircraft would mean to carefully resize their subsonic premium cabins concurrently and to attract new passengers, either from previously untapped demand or from the competition. As the required capital investment and the accompanying risk are high and the potential increase in profits is low, the major incentive left seems to be prestige, which might not suffice to convince financial stakeholders. Therefore, the first customers for supersonic airliners might be new entrants, propped up by potent capital investors who try to take away market share from the incumbents. The latter, however, will not simply endure the market disruption, but will employ economic countermeasures and political lobbying to fight the newcomers.

Moreover, airlines usually buy aircraft in batches to obtain quantity discounts and to benefit from economies of scale in operations by achieving high utilization of aircraft, crew, and maintenance facilities. Thus, supersonic airliners will primarily be acquired and operated in fleets that rotate through maintenance bases. City pairs of high demand, yet separated from the remaining networks (e.g. Lisbon - Luanda), will hardly qualify for supersonic airline service.

Manufacturer perspective. Concorde, the Tupolev Tu-144 and the American Supersonic Transport (SST) were in essence national, Cold-War vanity projects. Their expensive financing from public funds was justified through conveniently exaggerated market forecasts [11] and by spreading fears of the class enemy's domination in future air travel [12]. Renewed national supersonic projects seem unlikely due to those lessons from the past about sunken tax monies, hugely disappointing production numbers (20 for Concorde, 17 for Tu-144), and mixed public acceptance, as well as due to today's rise of environmental consciousness. Thus, commercial manufacturing appears to be the only way forward. At the same time and as for any new large aircraft type, a private OEM needs the real prospect of a few hundred sales that can amortize a multi-billion-dollar development and fabrication program.

Politics. Supersonic airliners face several political hurdles. Most challengingly, supersonic flight over land is prohibited in most of the world's countries due to the sonic boom that impacts the ground for nearly the entire supersonic phase of a mission. NASA and JAXA are dedicating significant effort to the research of technical means that make the boom sound softer and less disturbing. However, it is still unclear when those technologies will reach a level of maturity that makes them acceptable by the great majority of the public. For the time being, supersonic flight is limited to oceans and seas.

Further, supersonic aircraft inevitably burn significantly more fuel and cause more atmospheric emissions than their subsonic counterparts. Also, they cruise in altitudes that make them contestable for ozone layer depletion and inappropriate water vapor emission. With environmental consciousness globally on the rise, supersonic aircraft will probably face considerable public scrutiny, strict regulations, and perhaps some extra taxation locally. 


\section{Methodology of market assessment}

The following assessment's purpose is the comparison of the market for the S4 supersonic airliner in case of supersonic overland flight prohibition and permission, respectively.

As a basis, actual passenger numbers from the commercial database Market Intelligence by Sabre ${ }^{e}$ are used, namely the number of premium passengers (Business \& First Class) between their origin and their destination on a city-pair level, worldwide. These numbers are extrapolated into the future using inter-regional passenger number growth predictions by the Boeing Commercial Market Outlook ${ }^{\mathrm{f}}$. Table 2 shows the top 10 city pairs with respect to premium-class ticket revenue in the year 2033, 15 years from the basic data of 2018.

\begin{tabular}{|c|c|c|c|c|c|}
\hline Drigin & Destination & $\begin{array}{c}\text { Premium } \\
\text { Pax }\end{array}$ & $\begin{array}{l}\text { DFare } \\
\text { [USD] }\end{array}$ & $\begin{array}{l}\text { DLoS } \\
\text { [d] }\end{array}$ & $\begin{array}{l}\text { Dist. } \\
\text { [nmi] }\end{array}$ \\
\hline New York & London & 420,692 & 2,359 & 4.8 & 2,995 \\
\hline London & New York & 415,530 & 2,380 & 5.5 & 2,995 \\
\hline Hong Kong & London & 244,782 & 2,945 & 7.5 & 5,205 \\
\hline London & Hong Kong & 240,737 & 2,997 & 7.6 & 5,205 \\
\hline New York & Los Angeles & 545,749 & 1,063 & 3.5 & 2,130 \\
\hline Los Anngeles & New York & 546,663 & 1,095 & 3.9 & 2,130 \\
\hline Dubai & London & 257,227 & 2,238 & 6.1 & 2,951 \\
\hline London & Dubai & 260,287 & 1,877 & 6.3 & 2,951 \\
\hline London & Singapore & 163,414 & 3,143 & 7.4 & 5.879 \\
\hline Singapore & London & 158,435 & 3,364 & 7.6 & 5,879 \\
\hline New York & SanFrancisco & 389,654 & 1,308 & 3.1 & 2,225 \\
\hline SanFrancisco & New York & 367,682 & 1,311 & 3.4 & 2,225 \\
\hline London & Sydney & 133.757 & 3,209 & 10.9 & 9,187 \\
\hline Sydney & London & 143,405 & 3,616 & 11.0 & 9,187 \\
\hline Hong Kong & New York & 110,348 & 3,931 & 7.9 & 7,004 \\
\hline New York & Hong Kong & 106,077 & 3,822 & 8.3 & 7,004 \\
\hline Paris & New York & 166,998 & 2,428 & 5.8 & 3,151 \\
\hline New York & Paris & 167,799 & 2,556 & 6.1 & 3,151 \\
\hline London & SanFrancisco & 124,917 & 3,054 & 7.0 & 4,658 \\
\hline SanFrancisco & London & 128,416 & 3,285 & 6.6 & 4,658 \\
\hline
\end{tabular}

Table 2. Origin-destination premium passengers in 2033, top 10 w.r.t. total fare revenue.

(ØFare: average fare; ØLoS: average length of stay; Dist.: great-circle distance)

After putting the S4's aircraft performance data provided by JAXA (aerodynamic polars, engine maps, masses, mission segmentation) in our mission simulation tool [13], we found the S4's range (including $10 \%$ of fuel left for reserves) to be more than 3,800 nautical miles supersonic and 4,300 nmi subsonic (at Mach 0.95). This means that JAXA's initial range indication of 3,500 nmi supersonic was rather conservative.

From the comprehensive list of city pairs, those were pre-selected that have a minimum of 20,000 yearly premium passengers (i.e., 55 daily) and whose distance is below 3,800 nmi. We adopted the assumption of non-stop connections only, because:

- Supersonic airliners will have tight cabins due to the critical necessity of limiting aerodynamic wave drag.

- The seats will be about the size of Premium Economy, moderately reclining, but not lie-flat, which would take too much space. The flight is supposed to be fast and short anyway. Otherwise, tickets would probably become extremely expensive. This seat layout existed in Concorde and is also planned for the Boom Overture $^{g}$ supersonic airliner.

- A maximum-range mission in the S4 takes close to five hours when cruising all supersonic and longer when subsonic segments are necessary. Most premium passengers will refuse Premium-Economy-sized seats for longer flights that include refueling stops.

- The initial flight schedules will predominantly cater for origin-destination passengers on short business trips, so the airplanes will start early in the morning and will not wait for incoming flights.

- Flight time advantages are compromised by layovers. There will probably be connecting passengers anyway who come for the experience or for the prestige factor. However, they should not be planned for or relied on, at least initially.

\footnotetext{
e www.sabreairlinesolutions.com

f www.boeing.com/commercial/market/commercial-market-outlook/

$\mathrm{g}$ www.boomsupersonic.com
} 
This assumption implies that, e.g., all relevant trans-Pacific connections are excluded.

For the remaining 242 city pairs, overwater flight paths were designed according to an established methodology detailed in [13] $]^{\text {h }}$ Pairings that do not allow for a reasonable overwater flight route, e.g. New York - Los Angeles or Moscow - Beijing, were left out. The preliminary supersonic route networks for Japan and Paris are shown in Figure 7 and Figure 8, respectively.

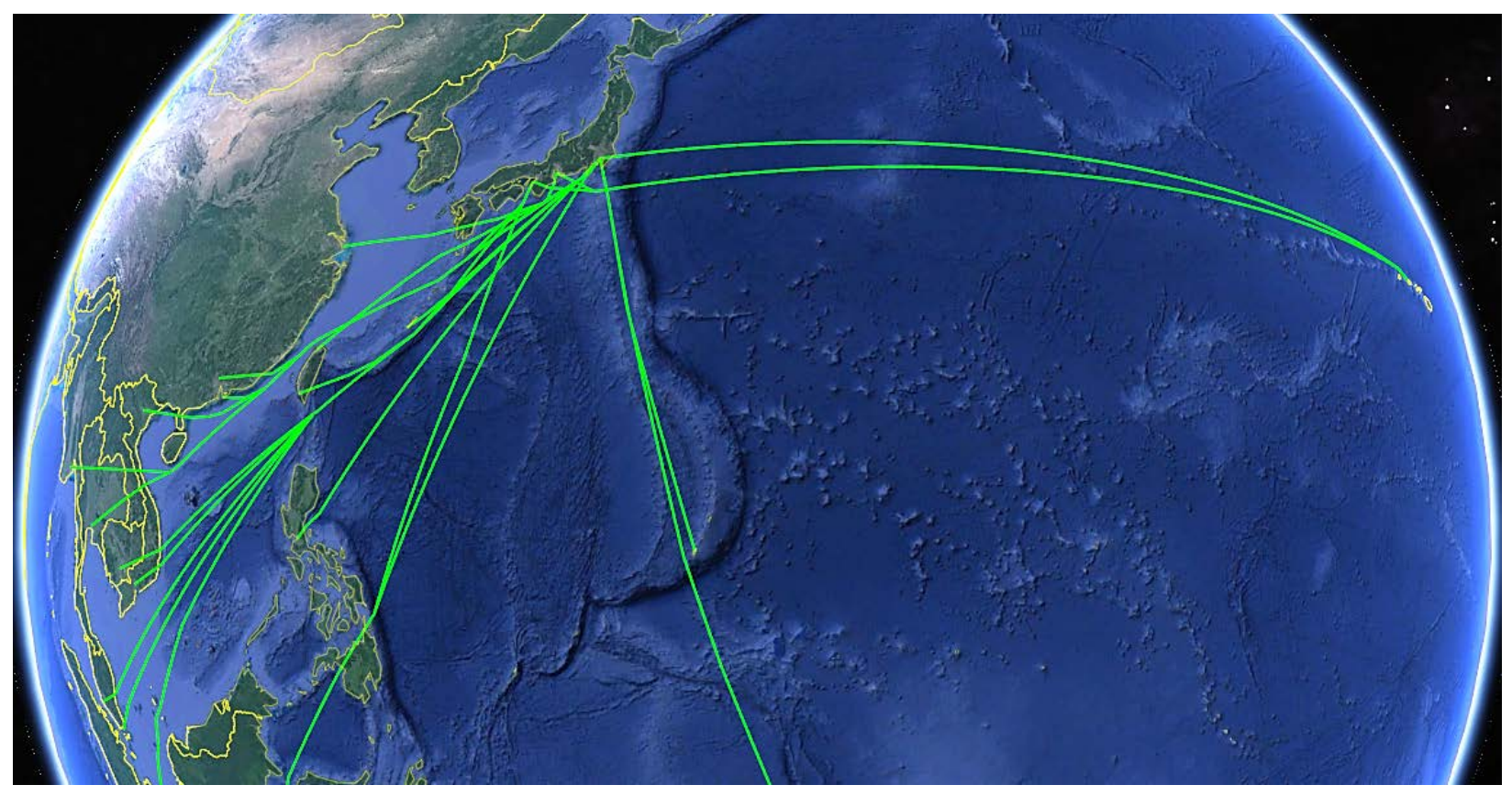

Figure 7. Supersonic route network for Japan [Google Earth].

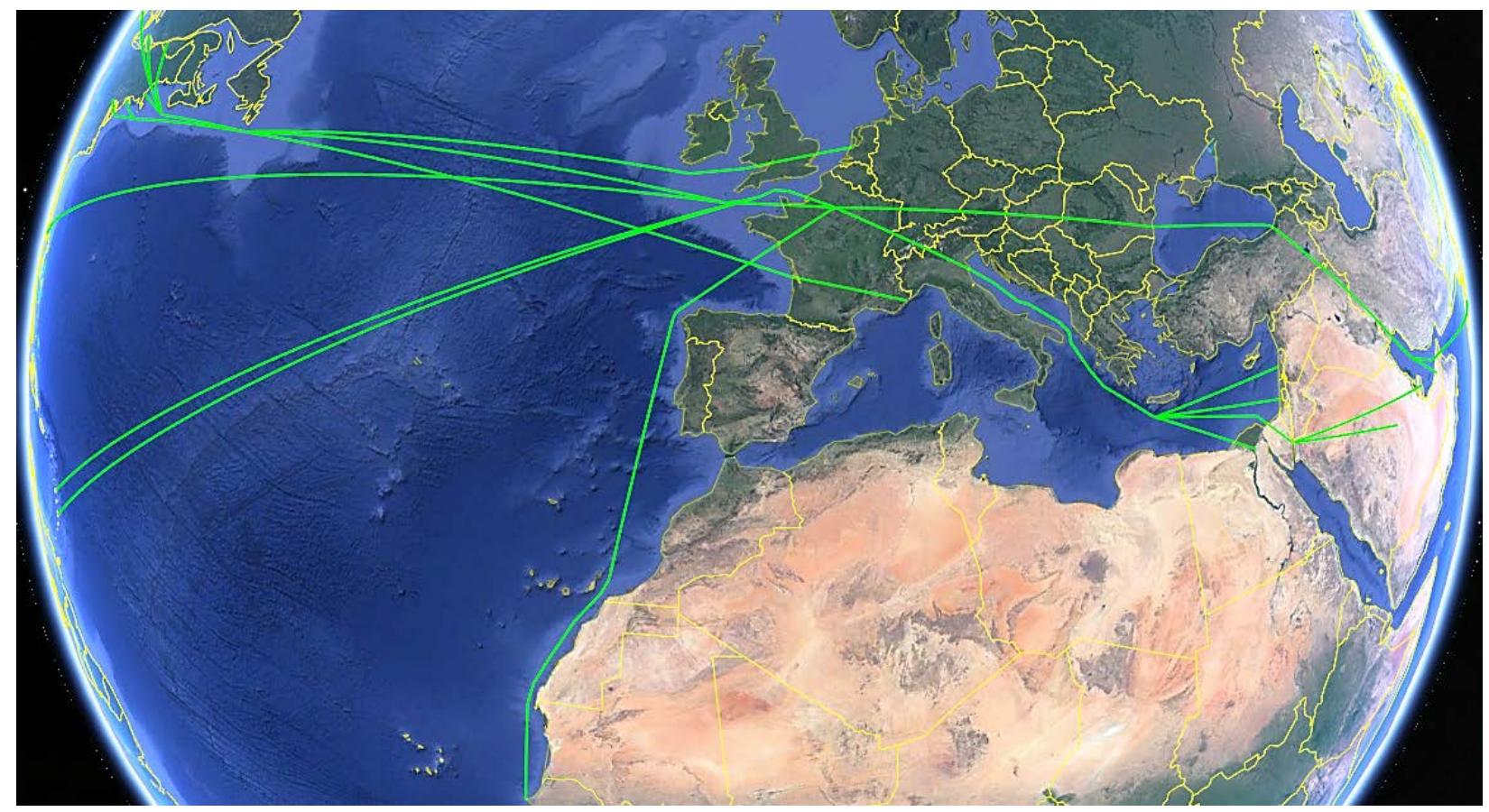

Figure 8. Supersonic route network for Paris (including Amsterdam and Nice) [Google Earth]

\footnotetext{
${ }^{\mathrm{h}}$ We considered also taking into account sonic boom carpets, as described in [14], but decided that it would not appreciably improve the study's outcome.
}

American Institute of Aeronautics and Astronautics 
Subsequently, we simulated the following missions for all city pairs (using a year-averaged atmosphere including winds, and adding average taxiing times at airports):

- A supersonic great-circle mission.

- A subsonic Mach 0.85 great-circle mission (to mimic a subsonic airliner).

- A rerouted flight (where available) at Mach 0.95 over land and Mach 1.6 over water.

Frome here on, the market assessment was separated: The all-supersonic missions apply to the scenario of supersonic overland permission, and the rerouted missions apply to the scenario of supersonic overland prohibition.

Both the absolute $\left(\Delta T_{a b s}\right)$ and the relative $\left(\Delta T_{r e l}\right)$ time advantages of supersonic versus subsonic flight were calculated for all city pairs where the mission simulation turned out successful (i.e., fuel/range sufficient). Figure 9 shows the distribution of time advantages over great-circle distance. For rerouted supersonic flight (right hand side), significantly fewer successful missions (and routes, respectively) are recorded, and the time advantages versus direct supersonic flight are significantly lower on average.

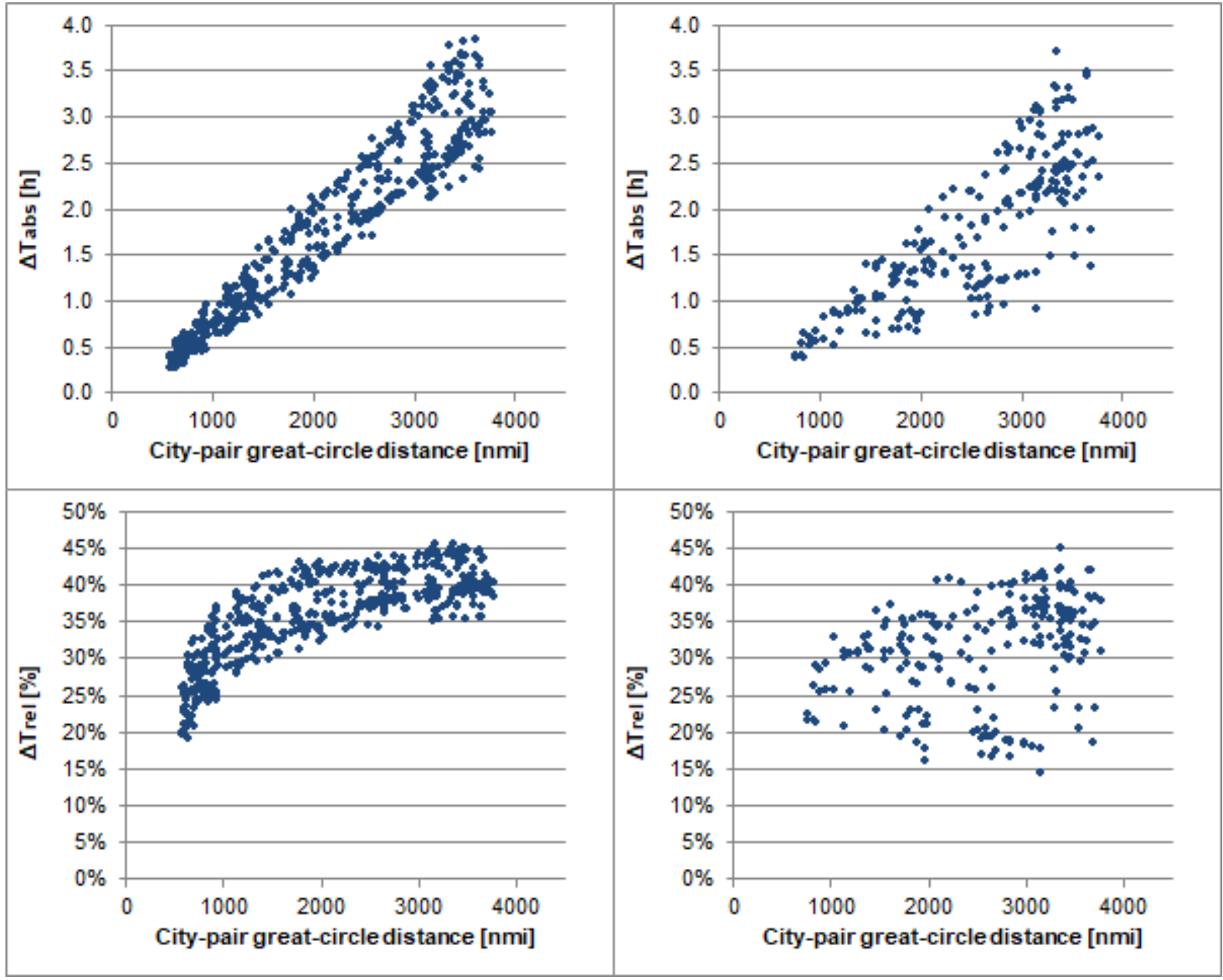

Figure 9. Time advantages of direct (left) and rerouted (right) supersonic flight versus subsonic flight

Next, the "inherent" suitability of each city pair regarding supersonic flight, irrespective of passenger numbers, was condensed in one figure of merit FoM. It contains:

- The average, distance-normalized willingness to pay of passengers $\Delta$ Yield (the higher, the better) relative to the global average.

- The average, distance-normalized length of stay at the destination $\Delta \operatorname{LoS}$ (the shorter, the better), relative to the global average.

- The absolute time advantage $\Delta T_{a b s}$ in relation to 3.5 hours as the arbitrary optimum $\Delta T_{a b s, o p t}$.

- The relative time advantage $\Delta T_{\text {rel }}$ in relation to $45 \%$ as the arbitrary optimum $\Delta T_{\text {rel,opt. }}$. 
FoM is calculated as follows:

$$
\text { FoM }=(1+\Delta \text { Yield }) \cdot(1-\Delta L o S) \cdot \frac{\Delta T_{\text {abs }}}{\Delta T_{\text {abs }, o p t}} \cdot \frac{\Delta T_{\text {rel }}}{\Delta T_{\text {rel,opt }}}
$$

Table 3 displays a sample of the gathered data at this point for the city pairs of highest revenue in 2033.

\begin{tabular}{|c|c|c|c|c|c|c|c|c|c|c|c|c|c|}
\hline Origin & Destination & $\begin{array}{c}\text { Premium } \\
\text { Pas }\end{array}$ & $\begin{array}{l}\text { UF are } \\
\text { [USD] }\end{array}$ & $\begin{array}{c}\text { Yield } \\
\text { [c/RPM] }\end{array}$ & $\Delta$ Yield & $\begin{array}{c}\text { DLoS } \\
\text { [d] }\end{array}$ & $\Delta \operatorname{LoS}$ & \begin{tabular}{|l|} 
Dist. \\
[nmi]
\end{tabular} & \begin{tabular}{|l|} 
BT [h] \\
M0.85
\end{tabular} & Sup & $\begin{array}{c}\text { T abs } \\
\text { [h] }\end{array}$ & $\begin{array}{c}\Delta \text { Trel } \\
{[\%]}\end{array}$ & Fo \\
\hline New York & London & 420,692 & 2,359 & 79 & $76 \%$ & 4.8 & $-23 \%$ & 2,995 & 5.9 & 3.7 & 2.3 & $38 \%$ & 1.2 \\
\hline London & New York & 15,530 & 2,380 & 79 & $78 \%$ & 5.5 & $-12 \%$ & 2,995 & 7.1 & 3.9 & 3.1 & $44 \%$ & 1.7 \\
\hline New York & Los Angeles & 545,749 & 1,063 & 50 & $12 \%$ & 3.5 & $-36 \%$ & 2,130 & 5.1 & 3.0 & 2.2 & $42 \%$ & 0.9 \\
\hline Los Angeles & New York & 546,663 & 1,095 & 51 & $16 \%$ & 3.9 & $-29 \%$ & 2,130 & 4.3 & 2.8 & 1.5 & $35 \%$ & 0.5 \\
\hline Dubai & London & 257,227 & 2,238 & 76 & $69 \%$ & 6.1 & $-1 \%$ & 2,951 & 6.9 & 4.0 & 2.9 & $43 \%$ & 1.4 \\
\hline London & Dubai & 0,287 & 1,877 & 64 & $42 \%$ & 6.3 & $2 \%$ & 2,951 & 5.9 & 3.6 & 2.3 & $39 \%$ & 0.8 \\
\hline New York & SanFrancisco & 389,654 & 1,308 & 59 & $32 \%$ & 3.1 & $-44 \%$ & 2,225 & 5.4 & 3.1 & 2.3 & $42 \%$ & 1.2 \\
\hline SanFrancisco & New York & 682 & 1,311 & 59 & $32 \%$ & 3.4 & $-39 \%$ & 2,225 & 4.5 & 2.9 & 1.6 & $36 \%$ & 0.7 \\
\hline Paris & New York & 998 & 2,428 & 77 & $72 \%$ & 5.8 & $-9 \%$ & 3,151 & 7.4 & 4.1 & 3.3 & $44 \%$ & 1.7 \\
\hline New York & Paris & 167,799 & 2,556 & 81 & $81 \%$ & 6.1 & $-5 \%$ & 3,151 & 6.2 & 3.8 & 2.4 & $38 \%$ & 1.1 \\
\hline Hong Kong & Beijing & 382,758 & 981 & 91 & $107 \%$ & 3.2 & $-29 \%$ & 1,076 & 2.5 & 1.7 & 0.8 & $31 \%$ & 0.4 \\
\hline Beijing & Hong Kong & 6,962 & 983 & 91 & $107 \%$ & 3.5 & $-22 \%$ & 1,076 & 2.5 & 1.7 & 0.8 & $33 \%$ & 0.4 \\
\hline Tokyo & Singapore & 5,084 & 1,533 & 54 & $20 \%$ & 4.2 & $-31 \%$ & 2,857 & 6.5 & 3.8 & 2.7 & $42 \%$ & 1.1 \\
\hline Singapore & Tokyo & 722 & 1,601 & 56 & $25 \%$ & 5.4 & $-12 \%$ & 2,857 & 5.9 & 3.7 & 2.2 & $37 \%$ & 0.7 \\
\hline Tokyo & Shanghai & 303,888 & 1,053 & 112 & $154 \%$ & 3.3 & $-26 \%$ & 940 & 2.6 & 1.6 & 0.9 & $37 \%$ & 0.7 \\
\hline Shanghai & Tokyo & 305,280 & 982 & 104 & $137 \%$ & 5.1 & $16 \%$ & 940 & 1.9 & 1.5 & 0.5 & $25 \%$ & 0.2 \\
\hline Hong Kong & Singapore & 306,148 & 957 & 69 & $56 \%$ & 3.1 & $-34 \%$ & 1,389 & 3.1 & 2.0 & 1.1 & $35 \%$ & 0.5 \\
\hline Singapore & Hong Kong & 305,795 & 929 & 67 & $51 \%$ & 3.5 & $-27 \%$ & 1,389 & 3.1 & 2.0 & 1.1 & $34 \%$ & 0.5 \\
\hline Hong Kong & Shanghai & 493,322 & 687 & 101 & $131 \%$ & 3.0 & $-28 \%$ & 678 & 1.6 & 1.2 & 0.3 & $22 \%$ & 0.1 \\
\hline Shanghai & Hong Kong & 481,023 & 433 & 64 & $45 \%$ & 3.2 & $-22 \%$ & 678 & 1.8 & 1.3 & 0.5 & $29 \%$ & 0.2 \\
\hline
\end{tabular}

Table 3. FoM of relevant city pairs in 2033, top 10 w.r.t. revenue (unconstrained scenario). (BT: block time)

For arriving at the possible market for supersonic aircraft on the basis of premium passenger numbers, the question arises of how many passengers will embrace supersonic service. Here, the parameter of basic market share $m s_{0}$ is introduced (like in our studies $\left.[15,16]\right)$. It indicates how many of the passengers would in principle be willing to switch to supersonic, whereas only the aircraft-related service itself is considered, but no city-pair specifics which are already covered by FoM. In principle, rather modest basic market shares should be expected, because:

- The supersonic seats will not be lie-flat like in Business or First class.

- The ticket prices will be high.

- The incumbent airlines will probably employ potent countermeasures (economically and politically) to protect their most profitable customer segment.

- Regulations might be sharpened and taxes might be raised if lavish and environmentally detrimental supersonic flight escalates.

Thus, three instances of basis market share $m s_{0}$ are taken into consideration: $10 \%, 25 \%$, and $50 \%$. A city pair's actual market share is the product of $F o M_{i}$ and $m s_{0}$.

The possible daily flight frequency $f_{i}$ on a city pair $i$ is calculated as follows ${ }^{\mathrm{i}}$ :

$$
f_{i}=\frac{n_{\text {pax }, i} \cdot m s_{0} \cdot F o M_{i}}{n_{\text {seats }} \cdot s l f \cdot 365}
$$

Table 4 shows the flight frequencies, the market shares, and the required number of airplanes for the highestfrequented city pairs in the speed-constrained scenario for each of the assumed basic market shares $m s_{0,1}=10 \%$, $m s_{0,2}=25 \%$, and $m s_{0,3}=50 \%$. One flight daily was set as a minimum frequency. The number of airplanes is calculated on the assumption of 10 hours daily utilization. It can be seen that some actual market shares significantly exceed the basic market shares, e.g. for London to Washington where $m s_{3}=82 / 83 \%$ and where the great majority of passengers would have to switch to supersonic (which seems questionable). In the unconstrained scenario, market shares surpassing $100 \%$ are calculated, which means that entirely new demand would have to be generated.

\footnotetext{
${ }^{\mathrm{i}}$ Number of passengers $n_{p a x}$, number of seats $n_{\text {seats }}$, seat load factor slf (globally assumed to be $75 \%$ )
} 


\begin{tabular}{|c|c|c|c|c|c|c|c|c|c|c|c|c|c|}
\hline \multirow[b]{2}{*}{ Drigin } & \multirow[b]{2}{*}{ Destination } & \multirow[b]{2}{*}{$\begin{array}{c}\text { Premium } \\
\text { Pas }\end{array}$} & \multirow[b]{2}{*}{$\begin{array}{c}\text { BT [h] } \\
\text { SSub }\end{array}$} & \multirow[b]{2}{*}{ FolM } & \multicolumn{3}{|c|}{$\mathrm{ms}_{0,1}=10 \%$} & \multicolumn{3}{|c|}{$\mathrm{msos}_{\mathrm{s}}=25 \%$} & \multicolumn{3}{|c|}{$\mathrm{ms}_{0,3}=50 \%$} \\
\hline & & & & & $\begin{array}{c}f_{1} \\
\text { [1/d] }\end{array}$ & mst & AlC 1 & $\underset{\text { [1/d] }}{f_{\mathrm{a}}}$ & $\mathrm{ms}_{2}$ & $\mathrm{AlC}_{2}$ & $\begin{array}{c}f_{0} \\
\text { [1/d] }\end{array}$ & $\mathrm{ms}_{3}$ & AlC: \\
\hline New York & London & 420,692 & 3.8 & 1.1 & 4 & $13 \%$ & 2 & 10 & $33 \%$ & 4 & 19 & $62 \%$ & 8 \\
\hline Paris & New York & 166,998 & 4.3 & 1.5 & 2 & $16 \%$ & 1 & 4 & $33 \%$ & 2 & 8 & $66 \%$ & 4 \\
\hline New York & Paris & 167,799 & 3.9 & 1.0 & 2 & $16 \%$ & 1 & 4 & $33 \%$ & 2 & 8 & $65 \%$ & 4 \\
\hline Hong Kong & Singapore & 306,148 & 2.1 & 0.5 & 0 & $0 \%$ & 0 & 2 & $9 \%$ & 1 & 5 & $22 \%$ & 2 \\
\hline Singapore & Hong Kong & 305,795 & 2.1 & 0.4 & 0 & $0 \%$ & 0 & 2 & $9 \%$ & 1 & 5 & $22 \%$ & 2 \\
\hline Boston & London & 81,108 & 3.6 & 1.2 & 0 & $0 \%$ & 0 & 2 & $34 \%$ & 1 & 4 & $68 \%$ & 2 \\
\hline London & Boston & 78,747 & 4.0 & 1.7 & 0 & $0 \%$ & 0 & 2 & $35 \%$ & 1 & 4 & $70 \%$ & 2 \\
\hline Shanghai & Singapore & 211,735 & 3.0 & 0.5 & 0 & $0 \%$ & 0 & 2 & $13 \%$ & 1 & 4 & $26 \%$ & 2 \\
\hline Hong Kong & Tokuo & 237,034 & 2.4 & 0.2 & 0 & $0 \%$ & 0 & 2 & $12 \%$ & 1 & 4 & $23 \%$ & 1 \\
\hline Tokuo & Hong Kong & 241,306 & 2.6 & 0.6 & 0 & $0 \%$ & 0 & 2 & $11 \%$ & 1 & 4 & $23 \%$ & 2 \\
\hline New York & Zurich & 62,972 & 4.3 & 1.1 & 0 & $0 \%$ & 0 & 2 & $43 \%$ & 1 & 3 & $65 \%$ & 2 \\
\hline Zurich & New York & 58,817 & 4.9 & 1.6 & 0 & $0 \%$ & 0 & 2 & $47 \%$ & 1 & 3 & $70 \%$ & 2 \\
\hline Frankfurt & New York & 70,554 & 4.7 & 1.3 & 0 & $0 \%$ & 0 & 1 & $19 \%$ & 1 & 3 & $58 \%$ & 2 \\
\hline New York & Frankfurt & 70,568 & 4.2 & 0.9 & 0 & $0 \%$ & 0 & 1 & $19 \%$ & 1 & 3 & $58 \%$ & 2 \\
\hline
\end{tabular}

Table 4. Fl. frequencies $f$, market shares $m s$, and no. of aircraft $A / C$ for different $m s_{0}$ (constrained scenario).

\section{Results of market assessment}

The calculated global market for the 50-seat S4 supersonic aircraft in case of supersonic overland flight permission and prohibition, respectively, is listed in Table 5. It can be seen that the market would more than double for all assumed $m s_{0}$ if prohibitions were lifted. In absolute numbers however, only the most optimistic case (unconstrained scenario, 47\% average passenger market share) can be considered encouraging for starting a development and manufacturing program.

\begin{tabular}{|r|ccc|ccc|}
\hline Supersonic overland flight... & \multicolumn{3}{|c|}{$\ldots$ prohibited } & \multicolumn{3}{c|}{...permitted } \\
\hline Basic market share $\mathrm{ms}_{0}$ & $10 \%$ & $25 \%$ & $50 \%$ & $10 \%$ & $25 \%$ & $50 \%$ \\
\hline World fleet & 8 & 47 & 120 & 20 & 99 & 285 \\
\hline Sum of daily flights & 14 & 78 & 210 & 38 & 180 & 534 \\
\hline Average frequency-weighted market share & $13 \%$ & $26 \%$ & $47 \%$ & $10 \%$ & $25 \%$ & $47 \%$ \\
\hline Maximum market share on a city pair & $16 \%$ & $47 \%$ & $83 \%$ & $16 \%$ & $55 \%$ & $118 \%$ \\
\hline
\end{tabular}

Table 5. Estimated world market for the 50-seat S4 supersonic aircraft, 2033

The distribution of the global fleet to airline bases and their respective subsidiaries is shown in Table 6 . Operations would obviously concentrate on the world's economic metropolises. Although it is questionable whether the total market would be profitable for an OEM, the paradox problem arises of whether the capacities of those particularly constrained airports could cater for dozens of new airplanes and their respective operations.

\begin{tabular}{|r|c|c|c|c|c|c|}
\hline Airline bases and subsidiaries & \multicolumn{2}{|c|}{ Frequency [1/d] } & \multicolumn{3}{|c|}{ Fleet } \\
\hline Basic market share $\mathrm{ms}_{0}$ & $10 \%$ & $25 \%$ & $50 \%$ & $10 \%$ & $25 \%$ & $50 \%$ \\
\hline New York & 12 & 37 & 110 & 5 & 18 & 58 \\
Boston & 0 & 3 & 11 & 0 & 2 & 6 \\
Washington & 0 & 3 & 10 & 0 & 2 & 5 \\
Chicago & 0 & 2 & 9 & 0 & 1 & 6 \\
Miami & 0 & 0 & 6 & 0 & 0 & 4 \\
Atlanta & 0 & 0 & 2 & 0 & 0 & 2 \\
Detroit & 0 & 0 & 1 & 0 & 0 & 1 \\
London & 6 & 32 & 81 & 3 & 18 & 43 \\
\hline Tokyo & 3 & 25 & 71 & 2 & 15 & 34 \\
\hline
\end{tabular}

10

American Institute of Aeronautics and Astronautics 


\begin{tabular}{|r|c|c|c|c|c|c|}
\hline Singapore & 3 & 21 & 58 & 2 & 12 & 29 \\
\hline Dubai & 2 & 11 & 37 & 1 & 8 & 22 \\
\hline Hong Kong & 4 & 15 & 36 & 4 & 7 & 17 \\
\hline San Francisco & 3 & 8 & 24 & 1 & 4 & 11 \\
\hline Los Angeles & 3 & 7 & 21 & 1 & 3 & 11 \\
\hline Paris & 2 & 5 & 16 & 1 & 3 & 10 \\
Amsterdam & 0 & 2 & 4 & 0 & 1 & 3 \\
Nice & 0 & 0 & 1 & 0 & 0 & 1 \\
\hline Frankfurt & 0 & 2 & 7 & 0 & 1 & 5 \\
Zurich & 0 & 2 & 4 & 0 & 1 & 2 \\
Geneva & 0 & 1 & 4 & 0 & 1 & 3 \\
Munich & 0 & 1 & 3 & 0 & 1 & 2 \\
Milan & 0 & 1 & 3 & 0 & 1 & 2 \\
Sydney & 0 & 2 & 6 & 0 & 1 & 3 \\
Melbourne & 0 & 0 & 5 & 0 & 0 & 4 \\
Perth & 0 & 0 & 4 & 0 & 0 & 3 \\
\hline
\end{tabular}

Table 6. Forecasted frequencies at hypothetical supersonic airline bases \& subsidiaries (unconstr. scenario)

In case the S4 would hold just 36 seats, the number of required airplanes would rise significantly, ceteris paribus; see Table 7. For making use of this market, the airplane could be designed for a lower seat count from the start.

\begin{tabular}{|r|ccc|ccc|}
\hline Supersonic overland flight... & \multicolumn{3}{|c|}{$\ldots$ prohibited } & \multicolumn{3}{c|}{...permitted } \\
\hline Basic market share $m \mathrm{~s}_{0}$ & $10 \%$ & $25 \%$ & $50 \%$ & $10 \%$ & $25 \%$ & $50 \%$ \\
\hline World fleet & 13 & 74 & 181 & 42 & 163 & 407 \\
\hline Sum of daily flights & 22 & 130 & 324 & 64 & 308 & 808 \\
\hline Average frequency-weighted market share & $10 \%$ & $24 \%$ & $45 \%$ & $10 \%$ & $24 \%$ & $45 \%$ \\
\hline Maximum market share on a city pair & $13 \%$ & $40 \%$ & $85 \%$ & $17 \%$ & $57 \%$ & $117 \%$ \\
\hline
\end{tabular}

Table 7. Estimated world market for a 36-seat S4 supersonic aircraft, 2033

\section{Discussion of market assessment}

The study quantifies the possible demand for supersonic airplanes in broad ranges. This reflects the circumstance that the market depends on many parameters and assumptions which are all subject to uncertainty. However, resting on the two main assumptions that passengers will mainly come from premium cabins and that supersonic airline service will largely be point-to-point and non-stop, the dimension of the possible market becomes clearer.

Coincidentally, it has to be cautioned that passenger numbers might not grow as strongly and regularly as predicted and that the forecast gets even more insecure in light of the present Corona pandemic's unprecedented drop in passenger demand and airline traffic, respectively.

Moreover, the present study would actually require a comparison of supersonic aircraft specifically designed for their respective regulatory environments. However, this would primarily reflect in somewhat higher ticket prices for low-boom airplanes due to their elevated fuel consumption, which is often offset by them not requiring overwater detours and saving fuel in consequence. We argue that the ticket-price influence on demand can be neglected by the assumption of pronounced price inelasticity of premium passengers, as long as fares stay in accustomed dimensions.

Further, it was demonstrated that the global supersonic S4 airliner market would barely be sufficient even for the most optimistic set of assumptions. The lower the seat capacity however, the more airplanes could (ceteris paribus) be filled from a static pool of premium passengers. DLR maintains the opinion that smaller supersonic airliners have better market chances because their capacity suffices for more city pairs and because their smaller "footprint" could avoid large disruptions as well as the accompanying opposition by competitors and politics.

Lastly, we estimate that the market for supersonic aircraft, if globally permitted to cruise over land in supersonic speed, would more than double in size, for it enables serving many important Eurasian and North-American city pairs. From this perspective, research of low-boom technologies makes immediate sense, even if it remains unclear when these technologies will be mature for real-world deployment. In addition, aerodynamic improvements could extend the cruise range for crossing the Pacific Ocean and for linking Japan to the mainland United States, which would further enlarge the market. 


\section{Conclusion}

This work detailed JAXA's approach and rationales to low-boom supersonic aircraft design, taking the S4 50seat airliner configuration as an example. JAXA utilized high-fidelity CFD simulations for engine-airframe integration, natural laminar flow delta wing, low-noise nozzle, and low-sonic boom design, thereby reaching the preliminary goal of 85 PLdB ground loudness. Also, a suite of sonic boom propagation codes was used for the generation of sonic boom ground loudness maps with respect to flight physics parameters.

Subsequently, DLR put the S4 airliner in two operational scenarios of supersonic overland flight prohibition and permission, respectively. Actual global origin-destination premium ticket sales numbers were projected into the future, constituting a potential passenger demand pool. Supersonic overwater routes were designed for the restrictive scenario, and aircraft performance data provided by JAXA were used for mission simulation. Eventually, it was found that the market for S4 supersonic airliners would more than double in size in case the supersonic overland ban was lifted. The total market would roughly encompass about 20 to 300 aircraft, depending on the degree of optimism. Coincidentally, it was argued that aircraft with fewer seats would find a bigger market.

\section{Acknowledgments}

The authors would like to thank J. Akatsuka and S. Koganezawa for constructing engine and sonic boom models for the S4-1.3.4 ${ }^{\text {th }}$ configuration. We also thank M. Kanamori for developing sonic boom analysis tools.

\section{References}

[1] Ueno, A., and Makino, Y., "Low-Boom and Low-Drag Design of Small Supersonic Transport Considering Propulsion Airframe Integration: JAXA Research and Devel. Memorandum,” JAXA-RM-18-001E, 2018.

[2] Nakahashi, K., Ito, Y., and Togashi, F., "Some challenges of realistic flow simulations by unstructured grid CFD,” International Journal for Numerical Methods in Fluids; Vol. 43, 6-7, 2003, pp. 769-783.

[3] Takaki, R., Yamamoto, K., Yamane, T., Enomoto, S., and Mukai, J., "The Development of the UPACS CFD Environment,” High Performance Computing, edited by A. Veidenbaum, et al., Vol. 2858, Springer, Berlin, Heidelberg, 2003, pp. 307-319.

[4] Ishikawa, H., Tanaka, K., Makino, Y., and Yamamoto, K., "Sonic-Boom Prediction using Euler CFD Codes with Structured/Unstructured Overset Method,” Proc. 27th Congress of the International Council of the Aeronautical Sciences (ICAS), 2010.

[5] Kanamori, M., Makino, Y., and Ishikawa, H., "Extension of Multipole Analysis to Laterally Asymmetric Flowfield Around Supersonic Flight Vehicle,” Journal of Aircraft; Vol. 56, No. 1, 2019, pp. 191-204.

[6] Yamamoto, M., Hashimoto, A., Aoyama, T., and Sakai, T., "A unified approach to an augmented Burgers equation for the propagation of sonic booms," The Journal of the Acoustical Society of America; Vol. 137, No. 4, 2015, pp. 1857-1866.

[7] Kanamori, M., Takahashi, T., Makino, Y., Naka, Y., and Ishikawa, H., "Comparison of Simulated Sonic Boom in Stratified Atmosphere with Flight Test Measurements,” AIAA Journal 56(7) 2743-55, 2018.

[8] U.S. Government Printing Office, "U.S. Standard Atmosphere," 1976.

[9] American National Standards Institute, "Method forCalculation of the Absorption of Sound by the Atmosphere,” 1995, ANSI S1.26-1995.

[10] Ishikawa, H., Makino, Y., Ueno, A., and Kanamori, M., "Sonic Boom Assessment in Primary Boom Carpet of Low-Boom Supersonic Airplane (NASA C25D),” AIAA Scitech 2019 Forum, San Diego, California, 2019.

[11] Davies, R. E. G., Supersonic (airliner) non-sense. A case study in applied market research, Paladwr Press, MacLean, Virginia, 1998.

[12] Conway, E. M., High-speed dreams. NASA and the technopolitics of supersonic transportation, 1945 - 1999, Johns Hopkins Univ. Press, Baltimore, Maryland, 2005.

[13] Liebhardt, B., Linke, F., and Dahlmann, K., "Supersonic Deviations: Assessment of Sonic-Boom-Restricted Flight Routing,” Journal of Aircraft; Vol. 51, No. 6, 2014, pp. 1987-1996. doi: 10.2514/1.C032591.

[14] Liebhardt, B., "Sonic Boom Carpet Computation as a Basis for Supersonic Flight Routing," AIAA Aviation 2019 Forum, Dallas, Texas, 2019.

[15] Liebhardt, B., Gollnick, V., and Luetjens, K., "Estimation of the Market Potential for Supersonic Airliners via Analysis of the Global Premium Ticket Market," 11th AIAA Aviation Technology, Integration, and Operations (ATIO) Conference, Virginia Beach, Virginia, 2011.

[16] Liebhardt, B., Lütjens, K., Tracy, R. R., and Haas, A. O., "Exploring the Prospect of Small Supersonic Airliners - A Case Study Based on the Aerion AS2 Jet," 17th AIAA Aviation Technology, Integration, and Operations Conference 2017, Denver, Colorado, 2017. 